\title{
Consórcios públicos e 0 atendimento à política nacional de resíduos sólidos por municípios do Cariri Paraibano
}

Allan Gustavo Freire da Silva allangfs@hotmail.com

Universidade Potiguar - UnP, Natal, Rio Grande do Norte, Brasil

Flávia Emanoela Sousa Pereira Quirino

flavia.espq@gmail.com

Universidade Potiguar - UnP, Natal, Rio Grande do Norte, Brasil

Laís Karla da Silva Barreto laisbarreto@gmail.com Universidade Potiguar - UnP, Natal, Rio Grande do Norte, Brasil

Williams Martinho Soares de Sousa

$\frac{\text { williams cgp@hotmail.com }}{\text { Universidade Potiguar - UnP, Natal, Rio }}$ Grande do Norte, Brasil

Manoel Pereira da Rocha Neto manupereira@unp.br

Universidade Potiguar - UnP, Natal, Rio Grande do Norte, Brasil

\section{RESUMO}

A Política Nacional de Resíduos Sólidos - PNRS estabelece as diretrizes para adequado gerenciamento dos resíduos sólidos. Objetivou-se, nesse trabalho, analisar a possível viabilidade de criação de consórcios de gestão de resíduos sólidos em municípios do Cariri Paraibano. Metodologicamente, utilizou-se, para coleta de dados primários, a aplicação de questionários em 10 municípios localizados na região do Cariri Paraibano, com a intenção de identificar, considerando o período de 2017, a então situação municipal sobre o gerenciamento dos resíduos sólidos; buscou-se ainda, avaliar as capacidades financeiras, bem como as possibilidades de investimento destes municípios. Para a aquisição de dados secundários, foram realizadas consultas aos sites do Tribunal de Contas do Estado da Paraíba e ao SAGRES Cidadão. Verificou-se que os municípios carecem de capacidade financeira e que não possuem adequada estrutura financeira para o cumprimento das exigências, de acordo com o que preceitua a PNRS. Desse modo, observa-se que a formação de um consórcio público, dispositivo administrativo-gerencial, assegurado constitucionalmente, apresenta-se como uma alternativa viável à promoção do atendimento à Lei 12.305/2010, no tocante à maioria dos municípios pesquisados.

PALAVRAS-CHAVE: Consórcios de Gestão. Municípios. Gestão de resíduos sólidos. Lei 12.305/2010. Capacidades financeiras. 


\section{INTRODUÇÃO}

O termo "resíduos sólidos", nomenclatura usada para identificar tudo aquilo que descartávamos após o consumo de um objeto, era intitulado "lixo". Não existia um olhar voltado à preservação do meio ambiente e o "lixo" não estava associado às questões de saúde pública. Com o agravamento dos problemas ambientais e das doenças causadas por vetores de doenças (baratas, moscas, mosquitos, ratos, entre outros), surgiu a necessidade de novas práticas voltadas ao tratamento dos resíduos que possibilitassem a minimização das agressões ao planeta e a diminuição da proliferação desses vetores.

Para melhor entendimento, torna-se importante fazer a distinção entre lixo e resíduo: lixo é tudo aquilo que não se pode aproveitar que não tem mais utilidade nem valor, é o que sobra após o consumo de alimentos ou objetos e que nos desfazemos para manter limpeza e desocupar espaço, era exatamente assim que todo material descartado por residências, comércios, indústrias, dentre outros ambientes, era considerado. Já o resíduo é tudo o que resta, que foi modificado pelo uso, mas que ainda pode ter valor, tratar o resíduo significa aproveitar o máximo dos materiais e energias gastos para produção de determinado objeto (BARATTO, et al. 2012). Ainda, a Lei 12.305/2010, em seu Art. 3ㅇ, XV, conceitua o termo rejeitos, como sendo "resíduos sólidos que, depois de esgotadas todas as possibilidades de tratamento e recuperação por processos tecnológicos disponíveis e economicamente viáveis, não apresentem outra possibilidade que não a disposição final ambientalmente adequada".

Trata-se, no entanto, de conceitos em constante amadurecimento teórico, uma vez que, diante de materiais identificados como resíduos, o que antes poderia ser visto como algo inútil e sem valor, passa a ser considerado seu potencial de reaproveitamento e sua capacidade de transformação e utilização criativa.

Partindo dessa diferença conceitual entre lixo e resíduo, a partir do entendimento do que, atualmente, pode ser aproveitado, dada as capacidades e limitações técnicas locais, é relevante destacar que para chegar à fase de tratamento dos resíduos, há vários processos que devem ser atendidos, principalmente nos municípios. Atentando às responsabilidades legais, conforme Art. 225 da Constituição Federal, é a administração municipal local responsável pela gestão dos resíduos dentro de seu território. Por este motivo, considerando o caso brasileiro, o tema gerenciamento dos resíduos sólidos chama atenção para os problemas que ainda não foram resolvidos pelos entes da federação e que estão relacionados às questões ambientais e a sobrevivência humana em todo planeta. Baratto et al. (2012, p.100) afirmam que:

A gestão dos resíduos sólidos se apresenta diferenciada em cada município brasileiro, mas é, em sua maioria, inadequada, visto que não tem merecido a devida importância por parte do poder público, sendo caracterizada pela ausência de infraestrutura, de profissionais capacitados e inclusive de informações. Isso compromete, cada vez mais, não somente a saúde pública, mas também os recursos naturais, em especial o solo e os recursos hídricos (BARATTO et al., 2012, p. 100).

A irresolução dos problemas por parte do poder público agrava a situação, desde 2010, com a publicação da Lei 12.305/2010, a qual instituiu a Política Nacional de Resíduos Sólidos - PNRS, gerando um novo desafio para a 
administração pública no país, uma vez que a PNRS trouxe consigo a obrigatoriedade dos órgãos, responsáveis pelos resíduos sólidos distribuídos em seu território, de organizarem a gestão desses resíduos por meio da elaboração dos Planos de Gestão Integrada de Resíduos Sólidos e de sua implementação (GEOTECHNIQUE, 2009), os quais devem ter como prioridades para gestão dos resíduos, conforme a supracitada lei, Art. 7으, inciso II, "não geração, redução, reutilização, reciclagem, o tratamento dos resíduos sólidos e disposição final ambientalmente adequada dos rejeitos".

Neste diapasão, de acordo com a Lei, 12.305, Art. 3으, inciso XIII, surge a exigência de implantação de padrões sustentáveis de produção e consumo, que venha "atender às necessidades das atuais gerações e permitir melhores condições de vida, sem comprometer a qualidade ambiental e o atendimento das necessidades das gerações futuras", deixando de priorizar apenas o lucro ou o consumo exacerbado (BRASIL, 2010, p.2).

Nesse sentido, uma das alternativas que podem ser utilizadas na administração municipal é a gestão consorciada dos resíduos sólidos, de acordo com o que preceitua a Constituição Federal Brasileira de 1988, em seu Art. 241, o qual assegura a possibilidade de consórcios públicos e convênios de cooperação entre os entes federados, ao autorizar a gestão associada de serviços públicos. Trata-se, portanto, de uma solução que possibilita o envolvimento coletivo, intermunicipal e/ou interestadual, por meio da utilização fracionada, parcelada, compartilhada e solidária de recursos financeiros e humanos por parte de cada ente federado.

Com a elaboração do Plano Estadual, consoante Art. 16ㅇ da Lei 12.305/2010, passa-se a dispor de um estudo que sugere os arranjos entre municípios em todo - Estado, o que facilita e incentiva a formação dos consórcios públicos. Considerando, sobretudo, as necessidades de informações atuais sobre os avanços no atendimento à Política Nacional de Resíduos Sólidos - PNRS e as condições financeiras dos municípios para realizarem investimentos na área de resíduos sólidos, esta pesquisa em tela foca-se, portanto, em estudos que possibilitem a identificação de capacidade e viabilidade financeira de 10 municípios da região do Cariri Paraibano quanto à possibilidade de formalização de um consórcio público, voltado essencialmente ao gerenciamento dos resíduos sólidos no território do Cariri.

Sendo assim, a partir da definição do tema escolhido para o estudo como problema de pesquisa apresenta-se o seguinte questionamento: os municípios do Cariri Paraibano possuem capacidades financeiras e técnicas-administrativas que justifiquem e viabilizem a criação de consórcios para gestão dos resíduos sólidos?

Diante do contexto e da problemática apresentada, este trabalho tem como objetivo geral analisar a possível viabilidade de criação de um consórcio de gestão de resíduos sólidos em municípios do Cariri Paraibano. Para o alcance do objetivo central proposto, tem-se como objetivos específicos: descrever a atual situação de municípios do Cariri Paraibano quanto ao tratamento de resíduos sólidos; avaliar a capacidade financeira dos municípios, os repasses de outras esferas governamentais e os valores investidos pelas prefeituras na área de gestão de resíduos sólidos; investigar possíveis parcerias entre instituições públicas e/ou privadas, além da disposição socioeconômica e hierárquica-administrativa que se organizam os municípios. 
Este trabalho assume atenção especial e justificativa, uma vez que a literatura especializada nas questões de planejamento urbano, desenvolvimento local e regional, administração pública e meio ambiente, apresenta lacunas no que se refere a diagnósticos gerenciais nos municípios, diante de políticas e exigências do governo federal, sobretudo, em contexto de escassez de dados e informações, sob a análise de municípios brasileiros, nordestinos, paraibanos, de pequeno porte, localizados no Cariri Paraibano. Entende-se, portanto, que com tais pesquisas, as compreensões sobre cenários, situações fiscais e capacidades administrativas dos municípios, possuem características facilitadoras para positivas transformações sociais, econômicas, preservação e conservação do meio ambiente.

Para consecução dos objetivos e contribuição com a literatura que trata sobre os resíduos sólidos, busca-se trazer informações no tocante às ações que foram ou serão executadas para tratamento dos resíduos sólidos e atendimento às determinações governamentais legais, diante da capacidade financeira dos municípios pesquisados.

\section{REFERENCIAL TEÓRICO}

Essencialmente, nesta revisão de literatura abordam-se temas, conceitos e discussões voltadas à administração pública municipal e à política de resíduos sólidos, sob a perspectiva dos consórcios públicos intermunicipais.

\subsection{Política Nacional de Resíduos Sólidos}

Considerando contextos tecnológicos e ambientes envoltos pelo consumo, o meio ambiente recebe todo material descartado após o uso de determinado objeto, o que possibilita a poluição do ar e nas águas. Surge então a preocupação em amenizar a agressão ao meio ambiente e minimizar os desastres ecológicos e ambientais. No Brasil, essa preocupação incentivou o governo a instituir a Política Nacional de Resíduos Sólidos, por meio da Lei no 12.305 de 02 de agosto de 2010 que dentre outras questões, definiu os Resíduos Sólidos como:

[...] material, substância, objeto ou bem descartado resultante de atividades humanas em sociedade, a cuja destinação final se procede, se propõe proceder ou se está obrigado a proceder, nos estados sólido ou semissólido, bem como gases contidos em recipientes e líquidos cujas particularidades tornem inviável o seu lançamento na rede pública de esgotos ou em corpos d'água, ou exijam, para isso, soluções técnica ou economicamente inviáveis em face da melhor tecnologia disponível (BRASIL, 2010, p.2).

Atenta-se ainda que, a Política Nacional de Resíduos Sólidos - PNRS, de acordo com o Art. 40 da supra lei:

[...] reúne o conjunto de princípios, objetivos, instrumentos, diretrizes, metas e ações adotados pelo Governo Federal, isoladamente ou em regime de cooperação com Estados, Distrito Federal, Municípios ou particulares, com vistas à gestão integrada e ao gerenciamento ambientalmente adequado dos resíduos sólidos (BRASIL, 2010, p.3). 
Sobre o tratamento adequado dos resíduos sólidos, antes da instituição da Política Nacional de Resíduos Sólidos - PNRS, a Lei 11.445/2007, que estabeleceu diretrizes nacionais para o saneamento básico, previu em seu Art. 2으, III, o manejo de forma adequada dos resíduos sólidos como princípio fundamental para prestação dos serviços de saneamento básico. Portanto, a gestão dos resíduos sólidos faz parte de um universo maior de medidas e ações, composto pelo saneamento básico. Esta Lei estabeleceu que o serviço público de limpeza urbana e de manejo de resíduos sólidos urbanos são considerados serviços de saneamento básico e são compostos pelas atividades de "coleta, transbordo, transporte, triagem, tratamento, disposição final”, Art. 2으, c, Lei 11.445/2007, além dos serviços de capina, varrição e poda de árvores.

Com a Lei 12.305/2010 os serviços de limpeza urbana e manejo de resíduos sólidos passaram a ser vistos de forma específica. Neste ponto, a PNRS prevê os instrumentos a serem utilizados para alcançar os objetivos desta política, os quais foram elencados nos incisos de I a XV do Art. 70 da referida Lei. Ainda, há distinção sobre a destinação dos resíduos e a disposição final dos mesmos, uma vez que o primeiro, significa qual o destino que os resíduos devem tomar, podendo ser a reutilização, a reciclagem, a compostagem, a recuperação o aproveitamento energético e outras formas admitidas pelos órgãos fiscais do meio ambiente, entre elas, a disposição final adequada, que, por sua vez, é a distribuição dos rejeitos em aterros, quando esgotadas as possibilidades de tratamento e recuperação dos resíduos.

\subsection{Consórcios Públicos}

Consórcio Público é a junção de dois ou mais entes da federação, podendo envolver entes da mesma esfera - municípios ou estados - como também de esferas diferentes - municípios e estados; estados e união; e municípios, estados e união -, cuja finalidade é a otimização e realização de um objetivo comum à todos os consorciados, salientado, pela Lei 11.107/2005.

Para Machado; Andrade (2014, p. 696):

Consórcios intergovernamentais são associações voluntárias entre entes governamentais para produção e compartilhamento de valores públicos, requerendo cooperação entre as partes interessadas na realização de objetivos comuns.

A forma consorciada surgiu como uma das soluções para modernização da administração pública, buscando métodos mais eficientes e eficazes de gestão. Foi a partir da Emenda Constitucional no 19/1998 a qual modificou o Art. 241 da Constituição Federal, que a União, Estados, Distrito Federal e Municípios ficaram autorizados a disciplinarem, por meio de Lei, as questões que abrangem os consórcios públicos. Anteriormente à Emenda Constitucional no 19/1998, os entes da federação não possuíam meios de cooperação, quando se tratava da mesma esfera do governo.

Após sete anos da EC no 19, as discussões foram levadas para o Congresso Nacional e o Projeto de Lei, encaminhado pelo Poder Executivo, deu origem à Lei no 11.107 de 6 de abril de 2005 que "dispõe sobre as normas gerais para a União, os Estados, o Distrito Federal e os Municípios contratarem consórcios públicos para a realização de objetivos de interesse comum" (BRASIL, 2005, p.1). 
As atividades realizadas pelos consórcios públicos são oriundas das transferências de serviços, as quais são responsabilidade dos entes associados. $\mathrm{Na}$ maioria das vezes, estes serviços possuem altos custos de administração e operacionalização, sendo mais viável serem executados por meio da ação consorciada, a qual dependerá de contrato de consórcio público, cuja celebração fica sujeita à ratificação do protocolo de intenções de acordo com a Lei aprovada pelo Poder Legislativo de cada ente, (TAVARES, ATHAYDE JÚNIOR, 2014); (OLIVEIRA; GALVÃO JÚNIOR, 2016). Com base no Art. 6ㅇ, incisos I e II da Lei 11.107/2005, (MACHADO; ANDRADE, 2014), define-se consórcio público como sendo:

[...] nova espécie de pessoa jurídica, consubstanciada de personalidade própria e autônoma, a quem é investido para a execução das tarefas de competência própria dos entes federados. Poderá também praticar atos em nome próprio, participando diretamente das relações jurídicas e constituir patrimônio específico (MADEIRA et al., 2013, p. 512).

No que se refere aos contratos firmados pelos consórcios públicos para execução de suas atividades, a Lei 11.107/2005 alterou a legislação que instituiu normas para licitações e contratos da Administração Pública. A Lei 8.666/93, em seus artigos 23, 24, 26 e 112, destaca como principais alterações a inclusão dos limites de valores estimados para o consórcio público em cada modalidade de licitação, o estabelecimento da dispensa de licitação nos contratos de programa com o consórcio público e disciplina a realização de processo licitatório pelo consórcio público, sendo o ente consorciado o celebrante do contrato administrativo.

Os atos de improbidade administrativa também foram previstos com a Lei do consórcio público, a qual também alterou a Lei 8.429/1992, que dispõe sobre as sanções aplicáveis aos agentes públicos, ao "celebrar contrato ou outro instrumento que tenha por objeto a prestação de serviços públicos por meio da gestão associada sem observar as formalidades previstas na lei;" e/ou "celebrar contrato de rateio de consórcio público sem suficiente e prévia dotação orçamentária, ou sem observar as formalidades previstas na lei.", são considerados atos de improbidade administrativa passíveis de sanções (BRASIL, 2005, p. 5).

A Lei 12.305/2010 que institui a Política Nacional de Resíduos Sólidos - PNRS, definiu o incentivo à adoção de consórcios ou de outras formas de cooperação entre os entes federados, com vistas à elevação das escalas de aproveitamento e à redução dos custos envolvidos, como instrumento da PNRS, ou seja, o consórcio público é visto pelo legislador como uma das alternativas e meios para o desenvolvimento da política pública de tratamento de resíduos sólidos e alcance dos resultados desejados, de forma que se torne possível a execução das funções dos entes por parte do consórcio, promovendo assim, ações necessárias e mais viáveis, financeiramente, para os entes associados.

A forma de gestão por meio de consórcios públicos apresenta-se como possível solução no conteúdo dos planos municipais de gestão integrada de Resíduos Sólidos, cumprindo o disposto na Lei 12.305/2010, Art. 19, inciso, III, "identificação das possibilidades de implantação de soluções consorciadas ou compartilhadas com outros Municípios, considerando [...] economia [...] 
proximidade dos locais estabelecidos e as formas de prevenção dos riscos ambientais" (BRASIL, 2010, p.10).

\section{METODOLOGIA}

Para esta pesquisa, utilizou-se de consultas e análises às determinações presentes na legislação vigente que regulamenta a Política Nacional de Resíduos Sólidos - PNRS (Lei no 12.305/2010), a Contratação de Consórcios Públicos (Lei no 11.107/2005) e as Diretrizes de Saneamento Básico (Lei no 11.445/2007).

No que se refere ao desenvolvimento da pesquisa, foram realizadas consultas ao Sistema Nacional de Informações sobre Saneamento - SNIS, a fim de avaliar quais os municípios, dentre os pesquisados, enviaram as informações do ano anterior sobre saneamento básico para o Governo Federal através da plataforma SNIS, além de consultas ao site do Ministério do Meio Ambiente - MMA.

Este trabalho, inicialmente, tinha como período de avaliação janeiro de 2016 a agosto de 2017. No entanto, considerando a escassez de dados, as fragilidades na transmissão, reunião e organização de dados em plataformas de transparência e de dados abertos, diante da falta de informações e inconsistências de dados do ano anterior, 2016, por parte das novas equipes de governo, que assumiram em transições, em algumas prefeituras avaliadas, foca-se, essa pesquisa em uma faixa temporal, de janeiro a agosto de 2017, o que proporcionará um diagnóstico e análise sobre o gerenciamento dos resíduos e o cumprimento de determinações legais, salientando ainda, a condição financeira das prefeituras neste período.

Em relação à pesquisa sobre a região do Cariri Paraibano, foram realizadas consultas à base de dados do Instituto Brasileiro de Geografia e Estatística - IBGE a fim de obter dados geográficos e populacionais dos municípios.

O Cariri faz parte das microrregiões do estado da Paraíba; geograficamente é dividido em duas microrregiões, Cariri Ocidental e Cariri Oriental, composta em sua totalidade por 29 municípios, conforme Quadro 1, todos de pequeno porte, onde o mais populoso é Monteiro com 33.007 habitantes - e o menos populoso é o município de Parari, com 1.786 habitantes, - de acordo com a população estimada pelo Instituto Brasileiro de Geografia e Estatística, realizado em 2018, sobre esses municípios.

Quadro 1 - Divisão geográfica do Cariri

\begin{tabular}{|c|c|c|}
\hline ORDEM & CARIRI OCIDENTAL & CARIRI ORIENTAL \\
\hline 01 & Amparo & Alcantil \\
\hline 02 & Assunção & Barra de Santana \\
\hline 03 & Camalaú & Barra de São Miguel \\
\hline 04 & Congo & Boqueirão \\
\hline 05 & Coxixola & Cabaceiras \\
\hline 06 & Livramento & Caraúbas \\
\hline 07 & Monteiro & Caturité \\
\hline 08 & Ouro Velho & Gurjão \\
\hline 09 & Parari & Riacho de Santo Antônio \\
\hline 10 & Prata & Santo André \\
\hline
\end{tabular}




\begin{tabular}{|c|c|c|}
\hline 11 & São João do Tigre & São Domingos do Cariri \\
\hline 12 & São José dos Cordeiros & São João do Cariri \\
\hline 13 & São Sebastião do Umbuzeiro & \\
\hline 14 & Serra Branca \\
\hline 15 & Sumé & \\
\hline 16 & Taperoá & \\
\hline 17 & Zabelê & \\
\hline
\end{tabular}

Fonte: Elaborado pelo autor, a partir de informações coletadas da base de dados do Instituto Brasileiro de Geografia e Estatística - IBGE (2017).

Destarte, para realização deste trabalho, foram escolhidos dez municípios, todos de pequeno porte - possuindo até 20 mil habitantes - advindos das duas microrregiões, as quais, para ampliação na coleta de informações, foi aplicado com os chefes integrantes da administração direta municipal, responsável pela pasta ligada à gestão de resíduos - um questionário com 44 questões, distribuídas em objetivas e subjetivas, para diagnosticar a situação dos municípios em relação à organização administrativa e aos recursos humanos e financeiros destinados ao tratamento e gerenciamento dos resíduos sólidos.

Sendo assim, conforme Figura 1, contendo lista de municípios distribuídos entre o Cariri Ocidental e Oriental, os municípios estudados foram: Barra de São Miguel, Camalaú, Caraúbas, Congo, Coxixola, Parari, São Domingos, São João do Tigre, Serra Branca e Sumé. Quanto aos procedimentos da pesquisa, trata-se de um estudo descritivo, realizado a partir do levantamento documental, aplicação de questionário, e de consultas a bancos de dados e portais governamentais. Quanto à sua natureza, assume um caráter de pesquisa quali-quantitativa, uma vez que se intenta descrever características estruturantes, a partir da aplicação de questionários semiestruturados e de consultas a portais e consolidados bancos de dados de instituições governamentais.

Figura 1 - Cariri Paraibano: Ocidental e Oriental

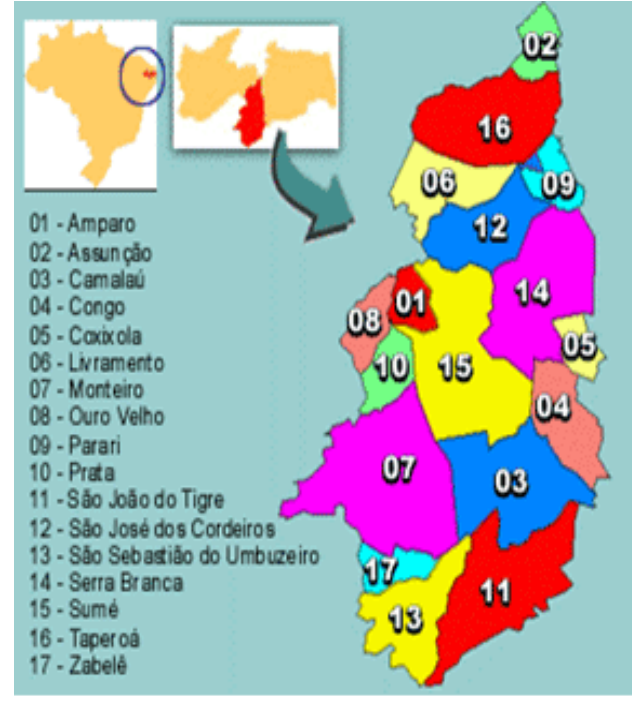

CARIRI OCIDENTAL

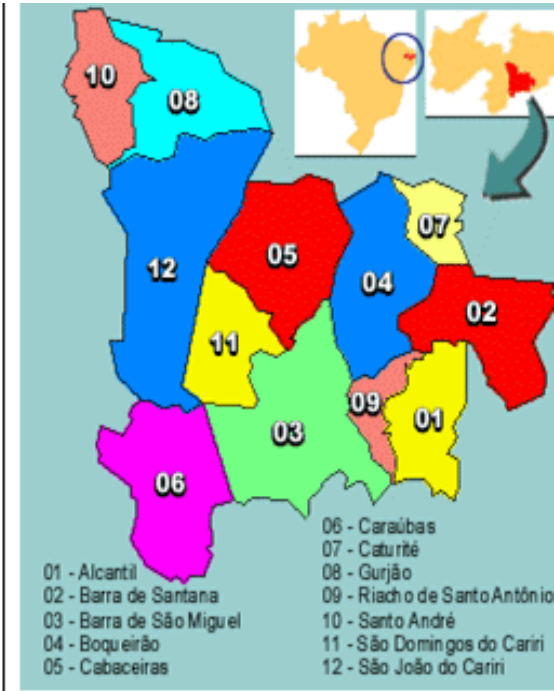

CARIRI ORIENTAL

Fonte: Milkpoint (2019). 
Após consultas ao Sistema Nacional de Informações de Saneamento - SNIS e das informações repassadas por meio do questionário aplicado aos municípios, constatou-se que todos os pesquisados ainda utilizam os lixões como destinação final dos resíduos. Sob posse dessas informações, foram realizadas consultas por meio do portal governamental de informações, e-SIC, além de pesquisas aos órgãos estaduais de fiscalização do meio ambiente, Superintendência de Administração do Meio Ambiente - SUDEMA e Superintendência do Instituto Brasileiro do Meio Ambiente e dos Recursos Naturais Renováveis - IBAMA, a fim de identificar se esses entes já foram autuados pela disposição final inadequada dos resíduos sólidos e/ou se pagam ou pagaram multas por esse motivo pesquisado.

A forma encontrada para buscar obter a realidade sobre a situação financeira dos municípios foi por meio de consultas ao site do Tribunal de Contas do Estado da Paraíba - TCE/PB, além do acesso livre ao SAGRES Cidadão, onde foram colhidas informações referentes ao período de janeiro a agosto de 2017, e obtidas as disponibilidades individuas de cada ente, mês a mês, possibilitando a avaliação das reservas e do equilíbrio financeiro das prefeituras estudadas. Diante dos valores obtidos, foram elaborados quadros que facilitam a visualização e auxiliam na compreensão das disponibilidades e demonstração financeira das contas das prefeituras.

\section{RESULTADOS E DISCUSSÃO}

Os resultados desta pesquisa foram obtidos por meio de duas fontes de pesquisa, a primeira foi a aplicação de um questionário com representantes públicos dos municípios paraibanos envolvidos, Barra de São Miguel, Camalaú, Caraúbas, Congo, Coxixola, Parari, São Domingos, São João do Tigre, Serra Branca e Sumé, o qual teve como tema e foco central: a situação do gerenciamento dos resíduos sólidos nos municípios do Cariri Paraibano. A segunda fonte de dados foi a busca de informações em bases de dados do Tribunal de Contas do Estado da Paraíba - TCE/PB, além do acesso livre ao SAGRES Cidadão, sobre as disponibilidades financeiras das prefeituras, o que serviu de base para avaliar as condições de investimento destes municípios, ante a gestão de resíduos sólidos.

\subsection{Informações dos Municípios}

Na primeira etapa foram identificadas as informações básicas de cada município e do responsável pelo preenchimento do questionário. Procurou-se no município a pessoa que teria maior número de informações sobre a situação do município quanto às questões ligadas aos resíduos sólidos. Na maioria dos casos, foram os secretários municipais que responderam, estando alocados nas diversas áreas de governo.

O que se percebe com a análise do Quadro 2, conforme população listada de acordo com a base de dados do Instituto Brasileiro de Geografia e Estatística (2010), a partir do preenchimento do questionário, é que há considerada diversidade nas funções dos responsáveis pelos assuntos levantados nesta pesquisa, o que demonstra a não priorização do poder público em ter uma 
secretaria específica, responsável diretamente pelas questões ligadas ao meio ambiente.

Quadro 2 - Informações dos municípios

\begin{tabular}{|c|c|c|c|c|}
\hline Município & População & $\begin{array}{c}\text { Cargo do } \\
\text { responsável pelas } \\
\text { informações }\end{array}$ & $\begin{array}{c}\text { Secretaria de Meio } \\
\text { Ambiente }\end{array}$ & $\begin{array}{c}\text { Secretaria } \\
\text { Responsável pelos } \\
\text { resíduos sólidos }\end{array}$ \\
\hline $\begin{array}{c}\text { Barra de São } \\
\text { Miguel }\end{array}$ & 5.611 & $\begin{array}{l}\text { Coordenador de } \\
\text { Desenvolvimento } \\
\text { Ambiental, } \\
\text { Sustentabilidade e } \\
\text { Resíduos Sólidos }\end{array}$ & NÃO & $\begin{array}{c}\text { Secretaria de } \\
\text { Desenvolvimento } \\
\text { Municipal }\end{array}$ \\
\hline Camalaú & 5.749 & $\begin{array}{l}\text { Secretário de } \\
\text { Administração }\end{array}$ & SIM & $\begin{array}{c}\text { Secretaria de } \\
\text { Agricultura, Meio } \\
\text { Ambiente e } \\
\text { Recursos Hídricos }\end{array}$ \\
\hline Caraúbas & 3.899 & $\begin{array}{l}\text { Secretário de } \\
\text { Planejamento, } \\
\text { Comunicação } \\
\text { Institucional e } \\
\text { Gestão }\end{array}$ & NÃO & $\begin{array}{l}\text { Secretaria de } \\
\text { Obras Públicas e } \\
\text { Serviços Urbanos }\end{array}$ \\
\hline Congo & 4.687 & $\begin{array}{l}\text { Secretário de } \\
\text { Infraestrutura }\end{array}$ & NÃO & $\begin{array}{l}\text { Secretaria de } \\
\text { Infraestrutura }\end{array}$ \\
\hline Coxixola & 1.771 & Controlador Interno & NÃO & $\begin{array}{l}\text { Secretaria de } \\
\text { Infraestrutura }\end{array}$ \\
\hline Parari & 1.256 & $\begin{array}{l}\text { Ex-Secretário de } \\
\text { Meio Ambiente e } \\
\text { atualmente } \\
\text { Vereador }\end{array}$ & $\begin{array}{c}\text { Na estrutura } \\
\text { organizacional SIM, } \\
\text { porém no momento } \\
\text { não há secretário } \\
\text { nomeado }\end{array}$ & $\begin{array}{l}\text { Secretaria de } \\
\text { Infraestrutura }\end{array}$ \\
\hline $\begin{array}{c}\text { São Domingos do } \\
\text { Cariri }\end{array}$ & 2.420 & $\begin{array}{c}\text { Secretário de } \\
\text { Agricultura, Meio } \\
\text { Ambiente e Recursos } \\
\text { Hídricos }\end{array}$ & SIM & $\begin{array}{c}\text { Secretaria de } \\
\text { Agricultura, Meio } \\
\text { Ambiente e } \\
\text { Recursos Hídricos }\end{array}$ \\
\hline São João do tigre & 4.396 & $\begin{array}{l}\text { Secretário } \\
\text { de Agricultura e } \\
\text { Meio Ambiente }\end{array}$ & SIM & $\begin{array}{c}\text { Secretaria de } \\
\text { Agricultura e Meio } \\
\text { Ambiente }\end{array}$ \\
\hline Serra Branca & 12.973 & $\begin{array}{c}\text { Secretário de } \\
\text { Desenvolvimento } \\
\text { Econômico e Meio } \\
\text { Ambiente }\end{array}$ & SIM & $\begin{array}{c}\text { Secretaria de } \\
\text { Desenvolvimento } \\
\text { Urbano, } \\
\text { Transportes e } \\
\text { Obras }\end{array}$ \\
\hline Sumé & 16.016 & $\begin{array}{l}\text { Diretora de Recursos } \\
\text { Humanos e Ex- } \\
\text { Secretária de } \\
\text { Administração }\end{array}$ & SIM & $\begin{array}{l}\text { Secretaria de } \\
\text { Obras e Serviços } \\
\text { Urbanos }\end{array}$ \\
\hline
\end{tabular}

Fonte: Elaborado pelo autor, com dados extraídos do questionário sobre a situação do gerenciamento de resíduos sólidos nos municípios do Cariri 
Observa-se que nenhum dos municípios entrevistados possui secretaria exclusiva de meio ambiente. Este espaço, assume a nomenclatura distinta, pulverizada entre outras pastas e assuntos, assim, as questões ambientais, para os municípios avaliados, encontram-se inseridas em demandas de outras secretarias, principalmente em secretarias de agricultura, as quais, muitas vezes, não possuem técnicos com expertise na área ambiental, sobretudo de gestão de resíduos, e que foram nomeados para atuarem em suas estruturas. A maioria dos servidores entrevistados possui uma atribuição diversa do gerenciamento de resíduos sólidos, mesmo sendo estas as pessoas que detêm o maior número de informações sobre o tema no município.

\subsubsection{Serviços executados nos municípios avaliados}

As questões propostas nesta etapa do questionário são relativas aos serviços executados nos municípios em relação aos resíduos sólidos. Todos responderam que o poder público municipal realiza a coleta de resíduos sólidos, e que não existe cobrança pelos serviços executados. Tem-se como resposta ainda, que nenhum município recebeu recursos de outras esferas governamentais para investimentos no gerenciamento dos resíduos sólidos, mas, considerando a legislação PNRS, isso se deve, dentre outras coisas, devido à falta de estrutura voltada a essas ações nos municípios avaliados, como também, ao não atendimento de prazos e demais exigências da Política Nacional de Resíduos Sólidos - PNRS aos entes municipais. Dessa forma, os serviços são custeados exclusivamente com recursos próprios da prefeitura, o que muitas vezes, torna precária a situação do gerenciamento, resumindo-se à coleta e disposição inadequada em lixões, sem nenhum tipo de tratamento.

Em relação ao patrimônio, todos os municípios possuem máquinas suficientes para melhorarem as áreas de tratamento dos resíduos sólidos. Em 2013 as prefeituras avaliadas receberam do Governo Federal, cada uma, cinco máquinas (caçamba basculante, retroescavadeira, enchedeira, motoniveladora, carro-pipa) o que possibilitou que aos municípios realizassem serviços que, anteriormente, eram inviáveis pelo custo da relação hora-máquina, paga a empresas terceirizadas. Alguns municípios já possuíam máquinas de grande porte, voltadas o desenvolvimento dessas atividades em seu patrimônio, antes mesmo da doação do Governo Federal, porém, o número foi duplicado e seu trabalho facilitado após receberem estas máquinas por meio do Programa de Aceleração do Crescimento - PAC.

No tocante à gestão de resíduos sólidos e ao questionário aplicado, mesmo com o maquinário disponível, a disposição final dos resíduos sólidos permanece sendo os lixões municipais. Observa-se, desse modo, um cenário em que, dentre os municípios avaliados, e maquinário disponível e adequado para o tratamento e coleta dos resíduos sólidos, somente o município de Sumé possui um caminhão compactador na coleta dos resíduos sólidos.

O Quadro 3 mostra o custo médio mensal com sistema de limpeza $x$ disponibilidade, considerando informações de agosto 2017. De acordo com os dados apresentados, apenas três municípios (Congo, Coxixola e Sumé) terceirizam os serviços de coleta, além disso, Sumé é o único município que também terceiriza os serviços de varrição. São João do Tigre e Serra Branca são os dois que dispõem 
de mais funcionários no sistema de limpeza urbana com 40 e 45 pessoas, respectivamente.

A partir da comparação da última coluna do Quadro 3, evidencia-se o custo médio mensal com sistema de limpeza em cada município e os valores constantes percebe-se uma desproporção entre os municípios:

Quadro 3 - Custo médio mensal com sistema de limpeza $\mathrm{x}$ disponibilidade agosto 2017

\begin{tabular}{|c|c|c|c|c|}
\hline Município & \multicolumn{2}{|c|}{$\begin{array}{l}\text { Total do custo médio } \\
\text { mensal com sistema de } \\
\text { limpeza }\end{array}$} & \multicolumn{2}{|c|}{$\begin{array}{c}\text { Disponibilidades, em agosto } \\
\text { de } 2017\end{array}$} \\
\hline Barra de São Miguel & $\mathrm{R} \$$ & - & $\mathrm{R} \$$ & $19.775,36$ \\
\hline Camalaú & $\mathrm{R} \$$ & $23.429,00$ & $\mathrm{R} \$$ & $311.777,77$ \\
\hline Caraúbas & $\mathrm{R} \$$ & $17.400,00$ & $\mathrm{R} \$$ & $59.666,61$ \\
\hline Congo & $\mathrm{R} \$$ & $32.880,00$ & $\mathrm{R} \$$ & $134.561,05$ \\
\hline Coxixola & $\mathrm{R} \$$ & $22.000,00$ & $\mathrm{R} \$$ & $808.700,95$ \\
\hline Parari & $\mathrm{R} \$$ & $26.500,00$ & $\mathrm{R} \$$ & $78.632,04$ \\
\hline São Domingos do Cariri & $\mathrm{R} \$$ & $5.000,00$ & $\mathrm{R} \$$ & $5.118 .120,36$ \\
\hline São João do tigre & $\mathrm{R} \$$ & $40.000,00$ & $\mathrm{RS}$ & $6.739,38$ \\
\hline Serra Branca & $\mathrm{R} \$$ & $60.110,00$ & $\mathrm{R} \$$ & $306.526,23$ \\
\hline Sumé & $\mathrm{R} \$$ & $57.900,00$ & $\mathrm{R} \$$ & $1.296 .445,01$ \\
\hline
\end{tabular}

Fonte: Elaborado pelo autor, a partir de informações de disponibilidades financeiras de janeiro a agosto de 2017 dos municípios (2017).

Ainda, relacionando-se ao Quadro 3, enfatiza-se os valores das disponibilidades desses dois municípios. São Domingos do Cariri possui o maior saldo nas contas, como disponibilidade em agosto de 2017, contudo, é o ente que menos investe em limpeza urbana. Analisando as informações de São João do Tigre, constata-se que o município está com as contas da prefeitura em seu menor índice, quando comparado com os demais municípios pesquisados, no entanto, é o município que assume o terceiro lugar no que se refere ao montante de investimentos direcionados ao sistema de limpeza urbana naquele município.

Pode-se considerar os dois extremos, o primeiro município da análise acima, poderia investir muito mais, inclusive em atendimento à Política Nacional de Resíduos Sólidos - PNRS, diante do saldo disponível em conta, o segundo, deveria economizar seus recursos financeiros para conseguir fazer uma reserva mínima, somada às políticas de planejamento, prevenção de endividamento e de investimentos na área ambiental. Sobre os serviços executados nos municípios analisados, observa-se as seguintes informações no Quadro 4: 
Quadro 4-Serviços executados nos municípios

\begin{tabular}{|c|c|c|c|c|c|c|c|c|c|c|}
\hline Municípios & $\begin{array}{l}\text { Operador do } \\
\text { Serviços de } \\
\text { coleta de RS }\end{array}$ & $\begin{array}{l}\text { Veículo } \\
\text { utilizado }\end{array}$ & $\begin{array}{l}\text { Númer } \\
\text { o de } \\
\text { máqui } \\
\text { nas } \\
\text { perten } \\
\text { centes } \\
\text { ao } \\
\text { patrim } \\
\text { ônio } \\
\text { munici } \\
\text { pal }\end{array}$ & $\begin{array}{l}\text { Núm } \\
\text { ero } \\
\text { de } \\
\text { funci } \\
\text { onári } \\
\text { os } \\
\text { no } \\
\text { servi } \\
\text { ços } \\
\text { de } \\
\text { colet } \\
\text { a }\end{array}$ & $\begin{array}{l}\text { Número } \\
\text { de } \\
\text { empreg } \\
\text { ados } \\
\text { terceiriz } \\
\text { ados no } \\
\text { serviços } \\
\text { de } \\
\text { coleta }\end{array}$ & $\begin{array}{l}\text { Número } \\
\text { de } \\
\text { funcioná } \\
\text { rios no } \\
\text { serviços } \\
\text { de } \\
\text { varrição }\end{array}$ & $\begin{array}{l}\text { Total de } \\
\text { pessoas } \\
\text { trabalhan } \\
\text { do no } \\
\text { sistema } \\
\text { de } \\
\text { limpeza } \\
\text { urbana }\end{array}$ & $\begin{array}{c}\text { Custo } \\
\text { médio } \\
\text { mensal } \\
\text { com mão } \\
\text { de obra no } \\
\text { sistema de } \\
\text { limpeza } \\
\text { urbana }\end{array}$ & $\begin{array}{l}\text { Custo médio } \\
\text { mensal com } \\
\text { serviços } \\
\text { terceirizado } \\
\text { s no sistema } \\
\text { de limpeza } \\
\text { urbana }\end{array}$ & $\begin{array}{l}\text { Total do } \\
\text { custo } \\
\text { médio } \\
\text { mensal } \\
\text { com } \\
\text { sistema de } \\
\text { limpeza }\end{array}$ \\
\hline $\begin{array}{c}\text { Barra de } \\
\text { São Miguel }\end{array}$ & $\begin{array}{c}\text { Administraçã } \\
\text { o direta }\end{array}$ & $\begin{array}{l}\text { Caminhão } \\
\text { basculante e } \\
\text { trator com } \\
\text { reboque }\end{array}$ & 8 & 9 & 0 & 14 & 23 & $\begin{array}{c}R \$ \\
29.767,00\end{array}$ & $\begin{array}{l}\mathrm{R} \$ \\
-\end{array}$ & $\begin{array}{c}\mathrm{R} \$ \\
29.767,00\end{array}$ \\
\hline Camalaú & $\begin{array}{l}\text { Administraçã } \\
\text { o direta }\end{array}$ & $\begin{array}{l}\text { Caminhão } \\
\text { aberto }\end{array}$ & 10 & 6 & & 15 & 21 & $\begin{array}{c}\mathrm{R} \$ \\
7.500,00\end{array}$ & $\begin{array}{c}\mathrm{R} \$ \\
15.929,00\end{array}$ & $\begin{array}{c}\mathrm{R} \$ \\
23.429,00\end{array}$ \\
\hline Caraúbas & $\begin{array}{l}\text { Administraçã } \\
\text { o direta na } \\
\text { sede e } \\
\text { terceirizado } \\
\text { no distrito }\end{array}$ & $\begin{array}{l}\text { Trator com } \\
\text { reboque e } \\
\text { caminhão } \\
\text { aberto }\end{array}$ & 8 & 3 & 1 & 14 & 18 & $\begin{array}{c}\mathrm{R} \$ \\
16.000,00\end{array}$ & $\begin{array}{c}\mathrm{R} \$ \\
1.400,00\end{array}$ & $\begin{array}{c}\mathrm{R} \$ \\
17.400,00\end{array}$ \\
\hline Congo & $\begin{array}{c}\text { Empresa } \\
\text { privada }\end{array}$ & $\begin{array}{l}\text { Caminhão } \\
\text { aberto }\end{array}$ & 8 & - & 4 & 17 & 21 & $\begin{array}{c}\mathrm{R} \$ \\
17.880,00\end{array}$ & $\begin{array}{c}\mathrm{R} \$ \\
15.000,00\end{array}$ & $\begin{array}{c}\mathrm{R} \$ \\
32.880,00\end{array}$ \\
\hline Coxixola & $\begin{array}{l}\text { Empresa } \\
\text { privada }\end{array}$ & $\begin{array}{l}\text { Caminhão } \\
\text { aberto e } \\
\text { caminhão } \\
\text { basculante }\end{array}$ & 5 & - & 3 & 11 & 14 & $\begin{array}{c}\mathrm{R} \$ \\
17.000,00\end{array}$ & $\begin{array}{c}\mathrm{R} \$ \\
5.000,00\end{array}$ & $\begin{array}{c}\mathrm{R} \$ \\
22.000,00\end{array}$ \\
\hline Parari & $\begin{array}{l}\text { Administraçã } \\
\text { o direta }\end{array}$ & $\begin{array}{l}\text { Caminhão } \\
\text { basculante }\end{array}$ & 8 & 5 & - & 23 & 28 & $\begin{array}{c}\mathrm{R} \$ \\
26.500,00\end{array}$ & $\begin{array}{l}\mathrm{RS} \\
-\end{array}$ & $\begin{array}{c}\mathrm{R} \$ \\
26.500,00\end{array}$ \\
\hline $\begin{array}{c}\text { São } \\
\text { Domingos } \\
\text { do Cariri }\end{array}$ & $\begin{array}{l}\text { Administraçã } \\
\text { o direta }\end{array}$ & $\begin{array}{l}\text { Caminhão } \\
\text { aberto }\end{array}$ & 6 & 5 & - & $\begin{array}{c}\text { os } \\
\text { mesmos } \\
\text { da } \\
\text { coleta }\end{array}$ & 5 & $\begin{array}{c}\mathrm{R} \$ \\
5.000,00\end{array}$ & $\begin{array}{l}\mathrm{R} \$ \\
-\end{array}$ & $\begin{array}{c}\mathrm{R} \$ \\
5.000,00\end{array}$ \\
\hline $\begin{array}{c}\text { São João do } \\
\text { Tigre }\end{array}$ & $\begin{array}{c}\text { Administraçã } \\
\text { o direta }\end{array}$ & $\begin{array}{c}\text { Trator com } \\
\text { reboque }\end{array}$ & 6 & 10 & 20 & 10 & 40 & $\begin{array}{c}\mathrm{R} \$ \\
30.000,00\end{array}$ & $\begin{array}{c}\mathrm{R} \$ \\
10.000,00\end{array}$ & $\begin{array}{c}\mathrm{R} \$ \\
40.000,00\end{array}$ \\
\hline $\begin{array}{c}\text { Serra } \\
\text { Branca }\end{array}$ & $\begin{array}{l}\text { Administraçã } \\
\text { o direta }\end{array}$ & $\begin{array}{l}\text { Compactado } \\
\text { r, Caminhão } \\
\text { aberto e } \\
\text { trator com } \\
\text { reboque }\end{array}$ & 9 & 15 & - & 30 & 45 & $\begin{array}{c}R \$ \\
43.110,00\end{array}$ & $\begin{array}{c}\mathrm{R} \$ \\
17.000,00\end{array}$ & $\begin{array}{c}\mathrm{R} \$ \\
60.110,00\end{array}$ \\
\hline Sumé & $\begin{array}{l}\text { Empresa } \\
\text { privada }\end{array}$ & $\begin{array}{l}\text { Compactado } \\
r\end{array}$ & 12 & 2 & 3 & 8 & 13 & $\begin{array}{c}\mathrm{R} \$ \\
7.900,00\end{array}$ & $\begin{array}{c}\mathrm{R} \$ \\
50.000,00\end{array}$ & $\begin{array}{c}\mathrm{R} \$ \\
57.900,00\end{array}$ \\
\hline
\end{tabular}

Fonte: Elaborado pelo autor, a partir de dados extraídos do questionário sobre gerenciamento de resíduos sólidos nos municípios do Cariri Paraibano

(2017).

Pode-se analisar, diante do Quadro 4, que não há uma padronização dos serviços. Se compararmos Serra Branca e Sumé, percebe-se uma grande diferença: o primeiro, executa os serviços por meio da administração direta, Sumé, por sua vez, executa os serviços por meio de empresa privada.

Sumé possui área urbana e população maiores e trabalha com um total de 13 pessoas terceirizadas na coleta e varrição, já Serra Branca, utiliza 45 pessoas. Na comparação entre Congo e São João do Tigre, que têm quase a mesma população, também se notou essa diferença, a primeira terceiriza os serviços de coleta e executa os serviços por meio de empresa privada, sendo a varrição, responsável por ocupar, no total, 21 pessoas nesta atividade. São João do Tigre, realiza todos os serviços por meio da administração direta e ocupa 40 pessoas, quase o dobro 
de pessoas que executam estes serviços no município do Congo, mesmo sendo municípios de portes iguais.

Em termos populacionais, Parari, Coxixola e São Domingos do Cariri são os três menores, porém, há uma disparidade muito grande em relação ao número de funcionários no sistema de limpeza urbana, Parari, a menor delas, ocupa 28 pessoas nos serviços, enquanto que São Domingos do Cariri ocupa 5 pessoas, as quais executam os serviços de coleta e varrição, simultaneamente.

Sobre as intenções de parcerias e análises sobre as possibilidades de consórcios com os demais municípios do Cariri Paraibano, São Domingos do Cariri e Sumé, foram os dois municípios que afirmaram não ter interesse em consorciarse com outros para atender à PNRS, são, no entanto, os dois municípios que possuem as maiores disponibilidades financeiras,. Os mesmos pretendem atingir o comprimento da PNRS de forma individual, mesmo não dispondo de recursos específicos para isso.

O município de Barra de São Miguel foi o único que recebeu recursos para instalação de um sistema de tratamento de resíduos sólidos, ou seja, na prática este deveria ser o município mais avançado para o alcance dos objetivos propostos do PNRS, de acordo com dados coletados no Portal da Transparência do Governo Federal, o convênio firmado com a Fundação Nacional de Saúde - FUNASA está em execução, o valor total do repasse é de $\mathrm{R} \$ 800.000,00$ (oitocentos mil reais) dos quais já foram liberados $\mathrm{R} \$ 400.000,00$ (quatrocentos mil reais). Com a construção e instalação de um de tratamento de resíduos sólidos neste município, uma alternativa seria a formalização do consórcio com os municípios interessados para que todos pudessem utilizar o aterro sanitário de Barra de São Miguel.

Sendo assim, cada ente teria suas atribuições e responsabilidades, promovendo possibilidades de viabilidade financeira aos entes municipais consorciados, considerando que a maior demanda de investimentos necessários, centraliza-se, justamente, na construção do aterro, o que neste caso, o município já dispõe de recursos específicos para isso.

Caso não ocorra acordo com o município de Barra de São Miguel, outra alternativa seria a formalização do consórcio com outro ente federado municipal, o que inicialmente, teria o custo de organização administrativa, elaboração do Plano Intermunicipal de Gestão Integrada de Resíduos Sólidos - PIGIRS, escolha das possíveis áreas, solicitações de licenças ambientais e elaboração de projetos de engenharia para construção de aterro sanitário. Somente após essas medidas, é que o consórcio está apto a pleitear recursos de convênios para construção de aterros, aquisição de máquinas e equipamentos.

\section{CONSIDERAÇÕES FINAIS}

Os municípios do Cariri Paraibano pouco destinaram recursos financeiros para o atendimento à Política Nacional de Resíduos Sólidos - PNRS, o único avanço foi a elaboração dos Planos Municipais de Gestão Integrada de Resíduos Sólidos PMGIRS, os quais ainda não saíram do papel para execução.

Um dos agravantes para o não cumprimento da legislação voltada aos faltam maiores e relevantes proposições políticas e iniciativa dos entes que 
compõem o poder público, tendo em vista que nos municípios mais bem estruturados financeiramente a situação não é diferente dos demais.

Uma alternativa para atendimento à Política Nacional de Resíduos Sólidos PNRS seria a formação de consórcios públicos para gerenciamento dos resíduos sólidos, visto que a situação financeira da maioria dos municípios não permite que resolvam os problemas relacionados aos resíduos sem envolver um trabalho coletivo, rateado entre municípios e entes associados.

O consórcio possibilita dividir custos e otimizar os serviços. A partir da avaliação realizada sobre as disponibilidades de recursos municipais feitas na pesquisa, observa-se que a maioria não possui capacidade financeira de se adequar individualmente, o que demanda, a partir dessa análise, maior capacidade de organização municipal, especificamente, no que se refere à criação de pastas e secretarias, diretamente voltadas à gestão de resíduos sólidos nos municípios. Observa-se que a estrutura municipal, não dispõe de atenção devida às ações transformadoras salientadas pela PNRS.

Desse modo, destaca-se que a forma consorciada de gestão dos resíduos sólidos, é uma possibilidade viável para o atendimento a Política Nacional de Resíduos Sólidos - PNRS, em cada município, diante da falta de profissionais qualificados na área ambiental, especificamente, para o tratamento adequado dos resíduos sólidos, assim como, a falta de recursos financeiros suficientes para investir em estrutura física, nas adequações necessárias para reeducação da população quanto às mudanças de hábitos que favoreçam a reutilização e/ou a reciclagem e na contratação de mão de obra para melhorar o manejo e tratamento dos resíduos. São entraves como estes que fazem com que municípios não avancem no cumprimento das políticas de resíduos sólidos.

Ainda, a estrutura do consórcio público permite que os consorciados disponham de equipe técnica qualificada para orientar o município sobre a melhor forma de gerenciar os resíduos. Com a contribuição dos consorciados, há o rateio de despesas, as quais seriam impraticáveis de forma individual, principalmente para municípios de pequeno porte, somadas a isso, ressalta-se que a comercialização dos recicláveis, torna-se mais vantajosa e atraente em maiores quantidades. Portanto, em termos de viabilidade financeira e de atendimento a PNRS, o consórcio pode ser considerado forma viável para os municípios do Cariri Paraibano. 


\title{
Public consortia and compliance with the national solid waste policy by municipalities of Cariri Paraibano
}

\begin{abstract}
The National Policy on Solid Waste - PNRS establishes the guidelines for proper management of solid waste. The objective of this work was to analyze the possible feasibility of creating solid waste management consortia in municipalities in Cariri Paraibano. Methodologically, for the collection of primary data, questionnaires were applied in 10 municipalities located in the Cariri Paraibano region, with the intention of identifying, considering the period of 2017 , the then municipal situation regarding the management of solid waste; it also sought to assess the financial capacities, as well as the investment possibilities of these municipalities. For the acquisition of secondary data, consultations were made to the websites of the Court of Auditors of the State of Paraíba and to SAGRES Cidadão. It was found that the municipalities lack financial capacity and do not have an adequate financial structure to meet the requirements, in accordance with the PNRS. Thus, it is observed that the formation of a public consortium, an administrativemanagerial device, constitutionally ensured, presents itself as a viable alternative to promoting compliance with Law 12.305 / 2010, with respect to most of the municipalities surveyed.
\end{abstract}

KEYWORDS: Management Consortia. Counties. Solid waste management. Law 12,305 / 2010. Financial capabilities. 


\section{REFERÊNCIAS}

BARATTO, D.S.; ROBAINA, L.E.S.. GODOY, M.B.R.B. Os resíduos sólidos e a abordagem geográfica: um estudo de caso em municípios de pequeno porte. Geosul, Florianópolis, v. 27, n. 54, p 99-115, jul./dez. 2012.

BRASIL. Constituição (1988). Constituição da República Federativa do Brasil: promulgada em 5 de outubro de 1988. Organização do texto: Juarez de Oliveira. 4. ed. São Paulo: Saraiva, 1990. 168 p. (Série Legislação Brasileira).

BRASIL. Lei № 8.429, de 2 de junho de 1992. Dispõe sobre as sanções aplicáveis aos agentes públicos nos casos de enriquecimento ilícito no exercício de mandato, cargo, emprego ou função na administração pública direta, indireta ou fundacional e dá outras providências. Disponível em:

http://www.planalto.gov.br/ccivil_03/LEIS/L8429.htm. Acesso em: 06 Abr. 2019.

BRASIL. Lei no 8.666 de 21 de junho de 1993. Regulamenta o art. 37, inciso XXI, da Constituição Federal, institui normas para licitações e contratos da Administração Pública e dá outras providências. Disponível:

http://www.planalto.gov.br/ccivil_03/LEIS/L8666cons.htm. Acesso em: 06 Abr. 2019.

BRASIL. Lei no 11.107, de 06 de abril de 2005. Dispõe sobre normas gerais de contratação de consórcios públicos e dá outras providências. Disponível em: http://www.planalto.gov.br/ccivil_03/_ato2004-2006/2005/lei/l11107.htm. Acesso em: 25 Mar. 2018.

BRASIL. Lei no 11.445, de 05 de janeiro de 2007. Estabelece as diretrizes nacionais para o saneamento básico. Disponível em:

http://www.planalto.gov.br/ccivil_03/_Ato2004-2006/2005/Lei/L11107.htm Acesso em: 19 Jul. 2018.

BRASIL. Lei no 12.305, de 02 de agosto de 2010. Institui a Política Nacional de Resíduos Sólidos; altera a Lei no 9.605, de 12 de fevereiro de 1998; e dá outras providências. Disponível em: http://www.planalto.gov.br/ccivil_03/_Ato20072010/2010/Lei/L12305.htm. Acesso em: 22 Mar. 2019.

BRASIL. Ministério do Meio Ambiente. Disponível em: http://www.mma.gov.br/cidades-sustentaveis/residuossolidos/cons\%C3\%B3rcios-p\%C3\%BAblicos. Acesso em: 02 Ago. 2018. 
GEOTECHNIQUE, Consultoria e Engenharia Ltda. Plano de Regionalização da Gestão Integrada de Resíduos Sólidos do Estado da Paraíba, 2009. Disponível em: http://www.mma.gov.br/cidades-sustentaveis/residuos-

solidos/cons\%C3\%B3rcios-p\%C3\%BAblicos. Acesso em: 18 Out. 2018.

IBGE, Instituto Brasileiro de Geografia e Estatística. Banco de dados, Cidades. Disponível em:

http://www.ibge.gov.br/cidadesat/xtras/perfil.php?codmun=250073\&search=par aiba. Acesso em: 06 mar. 2019.

IBAMA, Instituto Brasileiro do Meio Ambiente e dos Recursos Naturais Renováveis. Serviço de Informação ao Cidadão. Disponível em: http://www.ibama.gov.br/servico-de-informacao-ao-cid. Acesso em: 19 Out. 2018.

MACHADO, J.A.; ANDRADE, M.L.C. Cooperação intergovernamental, consórcios públicos e sistemas de distribuição de custos e benefícios. Rev. Adm. Pública, Rio de Janeiro, 48(3):695-720, maio/jun, 2014.

MADEIRA, C.G; MADEIRA, J.C.; MADEIRA, L.E. Consórcio Público: uma análise do instrumento da Política Nacional de Resíduos Sólidos. Revista Eletrônica do Curso de Direito da UFSM. p.509-520, 2013 - ISSN:1981-3694. Disponível em: https://periodicos.ufsm.br/revistadireito/article/view/8366. Acesso em: 20 Jun. 2018.

MILKPOINT, 2019. Disponível em: <https://bit.ly/2QRfGFT>. Acesso em: 07 Jun. 2019.

OLIVEIRA, T.B.; GALVÃO JUNIOR, A.C. Planejamento municipal na gestão dos resíduos sólidos urbanos e na organização da coleta seletiva. Eng Sanit Ambient, v.21, n.1, p.55-64, jan/mar, 2016. Disponível em: http://www.scielo.br/scielo.php?script=sci_arttext\&pid=S141341522016000100055\&lang=pt. Acesso em: 06 Set. 2018

TAVARES, P.T.; ATHAYDE JÚNIOR, G.B. Disposição final dos resíduos sólidos em 90 municípios paraibanos - análise da condição atual frente às exigências da política Nacional de Resíduos Sólidos. Revista Eletrônica de Gestão e Tecnologias Ambientais - GESTA. v. 2, n.1, p. 38-52, 2014 - ISSN: 2317-563X. 
Tribunal de Contas da União - TCU. Transferências Constitucionais e Legais. Disponível em: https://portal.tcu.gov.br/comunidades/transferenciasconstitucionais-e-legais/coeficientes-fpe-e-fpm/. Acesso em: 16 Out. 2018.

SUDEMA, Superintendência de Administração do Meio Ambiente. Serviço de Informação ao Cidadão. Disponível em: http://sic.pb.gov.br/. Acesso em: 05 Out. 2018.

SNIS. Sistema Nacional de Informações sobre Saneamento. Disponível em: http://www.snis.gov.br/. Acesso em: 06 Abr. 2019.

Recebido: 04 set. 2019.

Aprovado: 09 nov. 2019.

DOI: $10.3895 /$ rbpd.v9n1.9953

Como citar: SILVA, A. G. F.; QUIRINO, F. E. S. P.; BARRETO, L. K. S.; SOUSA, W. M. S., NETO, M. P. R.

Consórcios públicos e o atendimento à política nacional de resíduos sólidos por municípios do Cariri

Paraibano. R. bras. Planej. Desenv. Curitiba, v. 9, n. 1, p. 107-125, jan./abr. 2020. Disponível em:

$<$ https://periodicos.utfpr.edu.br/rbpd>. Acesso em: XXX.

Correspondência:

Allan Gustavo Freire da Silva

Av. Mal. Floriano Peixoto, 295 - Petrópolis - Natal, RN

Direito autoral: Este artigo está licenciado sob os termos da Licença CreativeCommons-Atribuição 4.0

Internacional.

cC) (i) 